\title{
Possibilities of Conversation between Posthumanism and Postcolonialism: A Case study of Public Bus Names
}

\author{
Saikat Chakraborty
}

\begin{abstract}
From the title it is very clear that the paper is not going to be bibliocentric but based on cultural artefacts, precisely bus names. Now, what is so posthuman in them? Why do I associate them to postcolonialism? Well, humanism and its Eurocentric dogmas have been under the critical lenses of posthumanists and antihumanists for long. The western model of the "ideal man" (vitruvian model) has gained its universal stature depending on the hegemonic insertion of 'otherization'. In other words, the universal idea of the human and humanism is essentially a western construct and is replete with the crime of domination, demonisation and othering. In this paper, I attempt to show human not as something concrete (a noun), but as a process, precisely, humanizing (a verb), that is based on the idea of privileging a particular race. It is here, posthumanism paves the way for a more emancipatory approach that critiques this idea of Europeans or the colonial masters as the moral guardians of the world. It is in this juncture I would like to bring out the conversation between postcolonialism and posthumanism to show how the insurrection of native voices work as a posthumanist approach. So, why bus names? As the argumentum folds, I would show how these bus names question the subjugation of native 'quirks' or instantiations of locally rooted belief by colonial modernity or its accompanying logic(s) of rationalistic knowledge perpetrated by Eurocentric humanism. Here by native 'quirks' I mean those so called naive, inadequate, disqualified and low-ranked knowledge's that Foucault calls 'popular knowledge'. In other words, in the paper, I would try to show the re-emergence of the 'popular knowledge' that is far from being common sense, but is actually a local form of knowledge that ruptures systematized power structures ordered by colonial rationality.
\end{abstract}

Keywords: Humanism, Eurocentrism, Posthumanism, Postcolonialism, Popular Knowledge.

The vision of this paper is to de-centre the western human model in order to bring out a possible conversation between two major theoretical schools that dismantle hegemonic dogmas, namely, posthumanism and postcolonialism. At the outset I want to make it clear to the readers why I have chosen these two schools.

To do so, first let me discuss why posthumanism? To understand that better I would first have an inquest into the question, what is humanism? Rosi Braidotti in her book The Posthuman argues that posthumanism is a western hegemonic construct perpetuated from the Protagoras's doctrine, "At the start of it all there is He: the classical ideal of 'Man'... 'the measure of all things"' (Braidotti, 2013, p.13) 
Later on, this was concretized and renewed by Leonardo da Vinci's vitruvian man as a part of the Italian renaissance, that, later on was universalized as the model of human perfectibility. This idea of universality started setting standards not only for individuals but also for their cultures. Therefore, historically humanism developed as a model of civilization that coincided Europe with the "universalizing powers of self-reflexive reason". (Braidotti, 2013, p,13) This transformation of humanism into a cultural hegemony gained its gigantic stature due to its defense by various philosophers such as Hegel and Husserl.

While on one hand Hegel with his self-aggrandizing views assumed that Europe is just not a geo-political entity but an attribute, and has the capability of lending its qualities on any other subject (irrespective of race, culture, identity, etc), on the other Husserl in his celebrated essay, 'The crisis of European Sciences' argues that Europe announces itself as the harbinger of self-reflexivity and critical reason thereby universalizing humanistic norms. This argument posits Eurocentrism into a place that does not entail it as a contingent matter but transcends it as a structural practice, embedded within cultural and pedagogical matters as well. (Braidotti, 2013, p.15)

Therefore, colonialism is essentially an off shoot of this Eurocentric humanism. Tony Davies in his book Humanism aptly points out, humanism fuelled "the imperial destinies of nineteenth century Germany, France, and supremely, Great Britain". (Davies, 1997, p.23) He further argues, "All humanisms, until now have been imperial...it is almost impossible to think of a crime that has not been committed in the name of humanity" (Davies, 1997, p.131) Now that humanism and colonialism had its own relational understanding, there should be a conversation between posthumanism and postcolonialism. Let me explain how,

In the book The Emancipatory Project of Posthumanism Erica Cudworth and Stephen Hobden argue that Posthumanism is the world after or beyond humanism. According to them, "The term posthumanism has been used in three principle ways: in the sense of a world after humanity; as forms of body modification and transhumanist 'uplift'; and, our own usage, in the sense of a world comprised of more than human.". It is a kind of resistance to humanistic ideals. (Cudworth \& Hobden, 2018, p.5) In this context Braidotti argues that this posthumanist turn was further more complicated by Edward Said's postcolonial angle. (Braidotti, 2013, p.16) Said in his book Humanism and Democratic Criticism writes, "Humanism as protective or even defensive nationalism is, I believe, a mixed blessing for its sometimes ideological ferocity and triumphalism..." According to him in a colonial setting the defense and revival of suppressed languages and cultural traditions and the assertion of national identity is explainable and understandable. (Said, 2004, p.37)

This sense of revival and assertion dismantles the Eurocentric humanism to imagine a world beyond these dogmas there by inserting a posthumanist turn to it with the aid of postcolonialism. Therefore, the supremacist idea of Eurocentrism has been critiqued both by posthumanism and postcolonialism. For long, the vitruvian model has perpetrated a structure that considers Europe as the center for reason and better humanistic creed while neglecting others as the inferior counterpart. But to rupture this structure we needed revival of the suppressed language and cultural tradition as Said would put it. This sense of revival would be a sense of "writing back" towards hegemonic structures. To put it more simply, I would like to quote Sartre as he in the preface to Fanon's The Wretched of the Earth writes, "the yellow and black voices still spoke of our Humanism, but only to reproach us with our inhumanity" (Braidotti, 2013, p.24).

It is very interesting how bus names have inculcated this sense of reproach and revival of suppressed cultural traditions into the public domain. Here I will give a few instances of such bus names. For that I would be referring to Goutam Kumar Dey's wonderful book called বাহনলিभि(BahonLipi) meaning vehicle inscriptions. One of the instances I would like to put 
forward is a bus named 'BABA CHANDANESHWAR' (বাবাচন্দনেশ্বর). The name is the earthly name of Lord Shiva and certainly refers to a locally rooted knowledge or belief that stands in sharp contrast to colonial subjugation because this asserts the native existence of the Sankari community living in the Digha-Odissa border. Three and a half kilometers from Digha-Odissa border there's a place called CHANDANESHWAR that entails the native history of Sankari community who established this temple. (Dey, 2010, p.69)

Another name that Dey puts forward is 'BABA PANCHANAN' (বाবাभश्ßानন) that he found in a bus from Baguiati-BBD Bag route. (Dey, 2010, p.71) PANCHANAN is the mixture of established Shiva in the Aryan society and an ancient native blood thirsty God. This name also inserts native quirkish belief as a sense of assertion of native peculiarity just like Amitav Ghosh uses বন্দুকীসওদাগরেরধাম, the shrine of the gun merchant as a trope for postcolonial resistance in his most recent work Gun Island.

Dey writes in some of the buses of Midnapore and South 24 Parganas other regional deities of Shiva can be found in the names such as, 'BABA BORO KANCHARI'(বাবাবড়কাঁচারী) and 'BABA ATESHWAR' (বাবাআটেশ্বর). In South 24 Parganas there is a place called Bakhrahat. The Banyan tree beside the Bakhrahat High School is worshipped as BORO KANCHARI and such cultural traditions have always remained on the fringes of history. ATESHWAR is worshipped as the saviour of cattle in the South 24 Parganas and as a dangerous devil in the Contai region of Midnapore. These names are instances of locally rooted popular instantiations of knowledge that Foucault calls 'le savoir des gens' or popular knowledges. (Gordon, 1980, p.82) Foucault argues that these popular local forms of knowledges are those blocks of history that were present but were subjugated and disguised within the body of functionalist and systematizing universal structures. These local forms of knowledges and cultural traditions have been branded as inadequate, naive, insufficiently elaborated and low ranked in the hierarchy of knowledge systems perpetrated by totalitarian universal views of humanism.

Foucault calls for the 'insurrection of subjugated knowledges' (Gordon, 1980, p.81) in order to rupture the history of subjugation regarding cultural traditions seeped in by universality of humanism that later on took a violent turn as colonialism. Now there are some wonderful names that I have collected through field work and I would like to discuss them here,

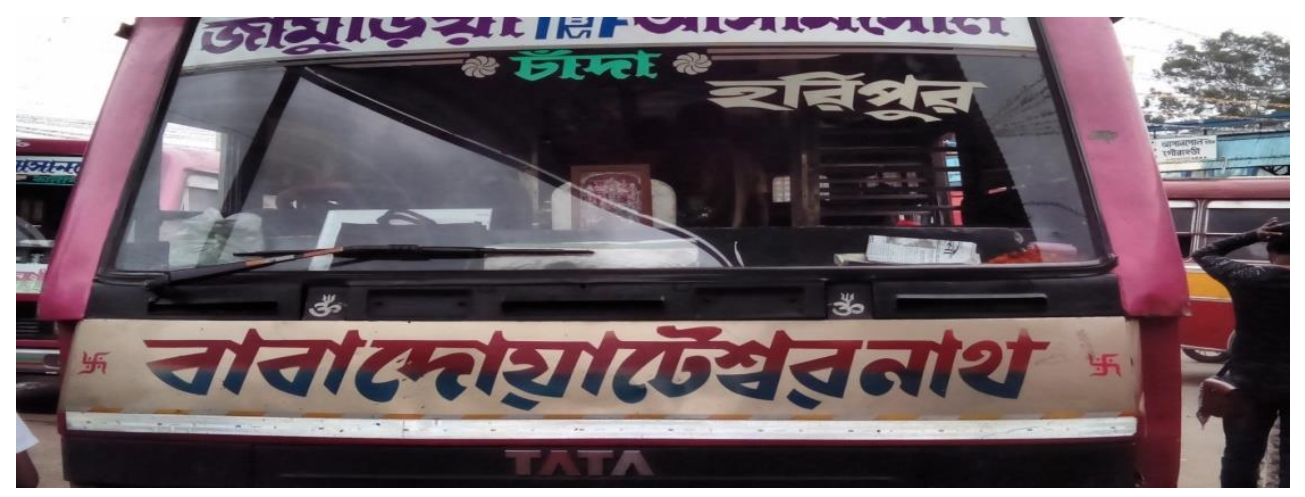

Figure 1 'BABA DOATESHWARNATH', ASANSOL BUS STAND, A BUS RUNNING FROM JAMURIA TO ASANSOL VIA HARIPUR, LENS: CANON 18-55MM, DATE: 18/09/2019, SELF CLICKED.

One of the names is 'BABA DOATESHWARNATH'(বাবাদোয়াটেশ্বরনাথ). The name is a fantastic embodiment of cosmopolitanism. Talking in terms of Indian contexts we 
understand that 'NATH' refers to Hindu God and the idea of 'DOA' or blessings is related to Islamic traditions. So, the name in itself amalgamates the religions and promotes the idea of 'cosmopolitanism'. Here I would like to refer to Yuval Noah Harari's book Sapiens: A Brief History of Humankind where Harari argues that monotheism has never been single or one, on the contrary, it has always been polyphonic. Harari writes, "In fact, monotheism, as it has played out in history, is a kaleidoscope of monotheist, dualist, polytheist and animist legacies, jumbling together under a single divine umbrella." (Harari, 2011, p.248) The scholars of religion have named this 'simultaneous avowal of different and even contradictory ideas and the combination of rituals and practices taken from different sources' as 'syncretism'. (Harari, 2011, p.248) Syncretism, according to Harari refers to a single and great world religion. The name here in discussion is a manifestation of such emancipating ideas such as syncretism.

Another name that entails such syncretic and cosmopolitanist ideas can be found in Goutam Kumar Dey's book Bahonlipi. In the book Dey depicts his personal experience that he had during his encounter with the owner and the conductor (owner's close relative) of the bus. Dey depicts, the bus was named as 'Manik Peer' (মानिকभीর). While enquiring the owner and the conductor Dey found them to be very reluctant on disclosing the genealogy of the name. However, after being assured of Dey's intentions and research needs they agreed to disclose the genealogy but had requested Dey not to publicize the registration number of the bus. On disclosure what Dey found out is starkly amazing and emancipatory. The owner and his family migrated to India in the post-partition scenario. Though Hindu by religion, the grandfather of the owner was attracted to Sufism and had converted to Islam. Here in India, they are identified as Hindu and also worship Hindu Gods and Goddesses for various social rituals. However, they have retained the religious fervor of the grandfather and take vows for the well being of their children to the 'PEER'. They also believe that for 'MANIK PEER' their economical prosperity has been achieved and thus the bus is devoted to 'MANIK PEER'. (Dey, 2010, p.170) The family entails a wonderful amalgamation and co-existence of different religions thereby inserting the ideas of cosmopolitanism and syncretism.

The names 'BABA DOATESHWARNATH' and 'MANIK PEER' just like the other names are also an instantiation of locally rooted knowledge and revival of subjugated cultural tradition thereby giving it a postcolonial turn as Said would put it. However, what interests me more is the posthumanist turn within them. The names themselves embody a perfect existence of religious harmony. Here I would like to refer to the idea of orderliness of the world. (Cudworth \& Hobden, 2018, p.73) The world is full of orders, as we understand from Newtonian physics and here, I mean in this context, orders of contradiction, meaning the various religious orders. However, this complexity of contradiction and chaos can be eradicated with better tools. (Cudworth \& Hobden, 2018, p.73) Here these scriptural-textual inscriptions work as that tool that eradicates these orders of contradiction and ushers in a posthumanist imagination beyond humanitarian discourses replete with religious disharmony and subsequent violence.

To discuss more on this posthumanist turn, I would refer to Bruno Latour's idea of Actant-Rhyzome-Ontology (Actor-Network-Theory) from the book The Emancipatory Project of Posthumanism. By Actant what Latour means is an agential unit that by its agency affects other actants. For him to act is to, "modify other actors through a series of trials that can be listed thanks to some experimental protocol". (Cudworth \& Hobden, 2018, p.57) Put simply Latour means that by acting one must affect the whole world and here I consider these buses to be the actants because by their constant presence within a humanist world and their agential insertion of these scriptural-textual images indeed change the 'worldview' of a humanist-colonialist paradigm.

These buses are so very important in this posthumanist paradigm because in the book 
Latour's idea about the "sociology of the social" and "the sociology of the associations" has been argued in light of posthumanities. (Cudworth \& Hobden, 2018, p.57) The sociology of the social has often neglected the non-humans and the inanimate but sociology for Latour is the sociology of associations. By associations he essentially means the association between the humans and the non-humans, here the association between the humans and these buses.

Now the term network or rhyzome for Latour is even more problematic and he defines it as 'an indicator of the quality of a text'. (Cudworth \& Hobden, 2018, p.59) Now this quality of a text is going to be very important because these inscriptions qualitatively embody a heterotopic space. To understand this better I would like to embark on the question, what is a heterotopia? It's a complex concept used by Michel Foucault first in the preface of his book The Order Of Things and later on in the essay 'Of Other Spaces'. In, The Order of Things Foucault depicts Heterotopias as,

"Heterotopias are disturbing, probably because they secretly undermine language, because they make it impossible to name this and that, because they shatter or tangle common names, because they destroy 'syntax' in advance, and not only the syntax with which we construct sentences but also that less apparent syntax which causes words and things (next to and also opposite one another) to hold together." (Preface to The Order of Things, p.xix)

Now this impossibility of not naming this and that brings in a posthumanist sense of emancipation because the bus itself becomes a heterotopia where the naming identity of a theist or atheist or Hindu or Muslim becomes a singular identity as the 'passenger' of a bus in the Asansol region called 'INDRARATH' (ইন্দ্ররথ) a Hindu religiously inscribed bus. Therefore, the heterotopic bus becomes a counter-space, a space 'no-where' (Foucault, p.5) that exists within the society and imagines a parallel emancipatory posthuman space.

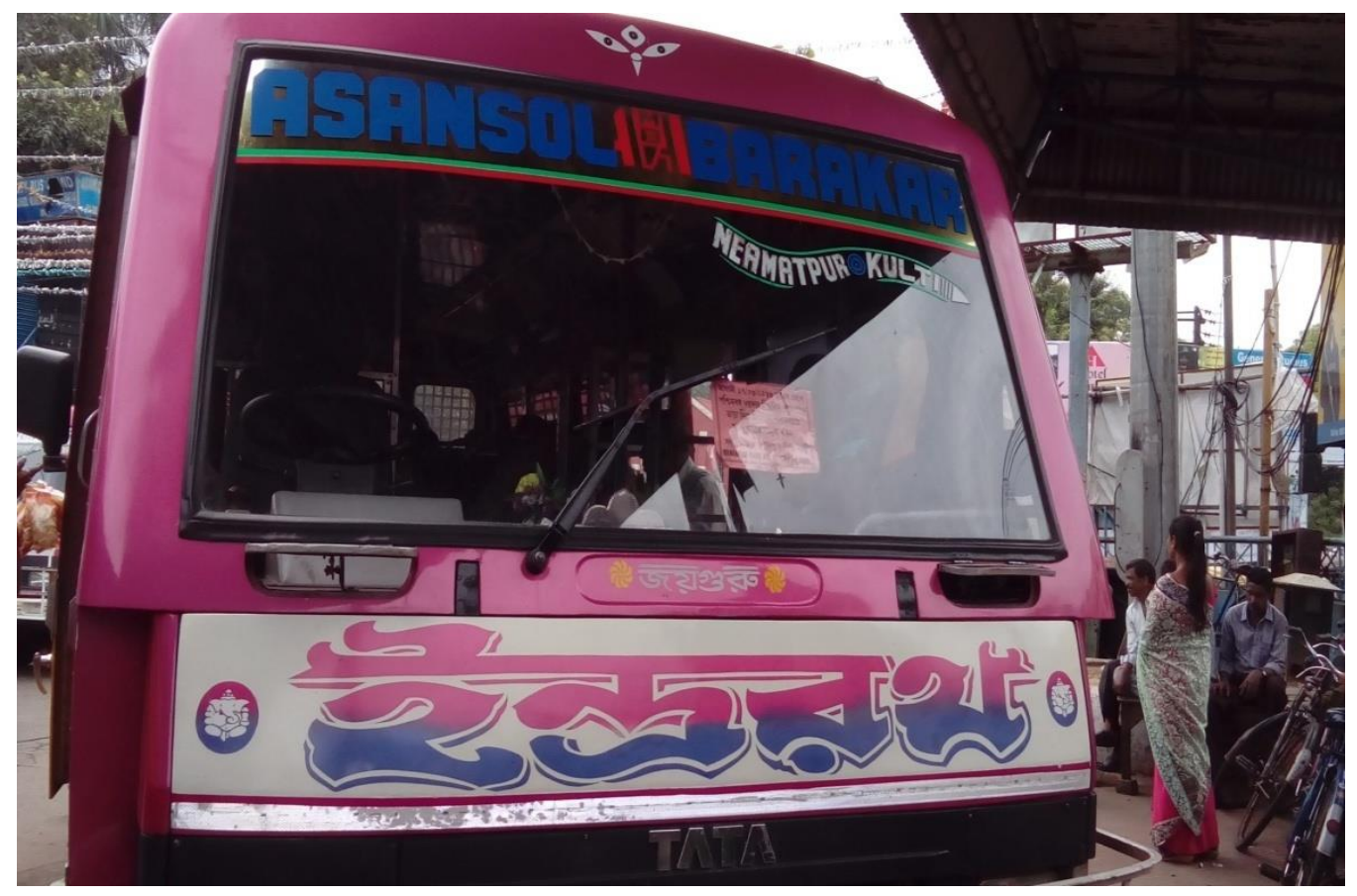

Figure 2 INDRARATH', ASANSOL BUS STAND, A BUS RUNNING FROM ASANOL TO BARAKAR, LENS: CANON 18-55 MM, DATE: 18/09/2019, SELF CLICKED.

Now, why do I call this place as a trans-space, a space no-where? To answer I would like to refer to Francesca Ferrando's recent book Philosophical Posthumanism. Francesca 
argues the importance of 'post' in posthumanism and provides us with a way towards this idea of no-where. According to her, 'post' in Latin means both 'behind' if related to space and 'after' if related to time. Here when I talk of a heterotopia, I intend to use 'post' in both its etymological contexts. For, Francesca 'post' is not a sharp break up but it denotes a continuity, discontinuity and transcendence. (Ferrando, 2019, p.66) This idea of transcendence is very important for my paper because here in a heterotopic space I am obviously looking for emancipation, transcendence from religious, humanist, colonial and cultural violence. This sense of transcendence eventually merges into the idea of a space everywhere, in Francesca's terms, the 'post' becomes a passage from somewhere to everywhere, in other words a no-where". Now the question is, does this no-where mean an imaginative space that does not exist in reality? Not really, on the contrary it means a counter space for emancipation, a space that does not entail the hegemonic discourses of other existing spaces such as the society. These ideas of 'everywhere' and 'no-where', then essentially mean a space for rhyzomic ontology, a space for all, a space for co-existence.

This discussion of the revival of local knowledges and posthumanist emancipation with the aid of syncretism and cosmopolitanism can be taken forward by referring to instances of quirkish names put forward by Dey in his book BahonLipi. There are some names such as 'SATBON' (সাতবোন) or 'SATVOUNI' (সাতভৌনি). These names, on one hand, are perfect instances of locally rooted knowledges and revival of suppressed culture because these Goddesses have been worshipped in the remote villages of Odissa, West Bengal and Tripura. The idea of 'SATBON' or seven sisters derives from the Goddesses such as 'SONKINI' (সনোকিনি), 'RONOKINI' (রনকিনি), 'CHOMOKINI' (চমকিনি) etc. On the other hand, in the Islam religion dominated places of South 24 Parganas these Goddesses are also worshipped as seven sisters but in a different name, i.e. 'SATBIBI' (সাতবিবি), comprised of 'OLABIBI' (ওলাবিবি), 'JHOLABIBI' (ঝোলাবিবি), 'ASANBIBI' (আসানবিবি), 'MOREEBIBI' (মড়িবিবি) etc. (Dey, 2010, p.170) Thus, manifestly we understand that the different names in different religions entail similarities in order to usher in a sense of co-existence of different religions that promote a world beyond humanity or a posthumanist regime so to speak.

Now to comment on the postcolonial aspect of these names we would have to understand the genealogy of these names. Dey writes that these are the names of Goddesses of disease. Then, what is the efficacy of inscribing the names of Goddesses of disease on one's bus? The answer would be very simple, as Dey writes, the reason comes from the fear of unprecedented road accidents. These road accidents can prove fatal to the workers of the bus as well as the owner because their lives due to these accidents can be threatened physically as well as economically. The bus in a sense provides sustenance to the families of the owner and the workers and the accident might ruin the schema altogether. Therefore, in a native belief these buses have been dedicated to the Goddess of disease in order to prevent fatality. So, we understand that these names not only insurrect quirkish locally rooted popular beliefs but also instantiate a sense of emancipatory syncretism in order to bring in a postcolonial as well as posthumanist turn within the ambit of public sphere.

The sense of revival in case of the language as Said's argument in the Humanism and Democratic Criticism can be wonderfully depicted through another name or inscription that I came across during my field work.

The name is 'NAZRUL INVERSITY'. Here the name refers to the university where currently I am studying in, Kazi Nazrul University. Here 'INVERSITY' is not a misspelled word but it is the instantiation of a local Bengali dialectic rampant in Asansol region. So, we understand the resurrection or in Foucauldian terms insurrection of these subjugated language and cultural traditions contribute to the phenomenon of postcolonial resistance. To concretize this idea of postcolonial resistance here I would like to refer to Ngugi Wa Thiongo's book Decolonising the Mind: The Politics of Language in African Literature. In the introduction of 
the book the author argues that the biggest weapon that the colonial masters have directed to the natives is what he calls the 'cultural bomb'. He writes, "the effect of a cultural bomb is to annihilate a people's belief in their names, in their language, in their environment, in their heritage of struggle, in their unity, in their capacities, and ultimately in themselves. (Thiongo, 2007, p.3) Therefore, the natives look at their nativity as one kind of a wasteland of nonachievement and therefore the sense of distancing from the nativity creeps in. However, these bus names revive these suppressed languages, cultures and beliefs in order to "speak the united language of struggle contained in each of their languages" as Thiongo would put it. (Thiongo, 2007, p.3)

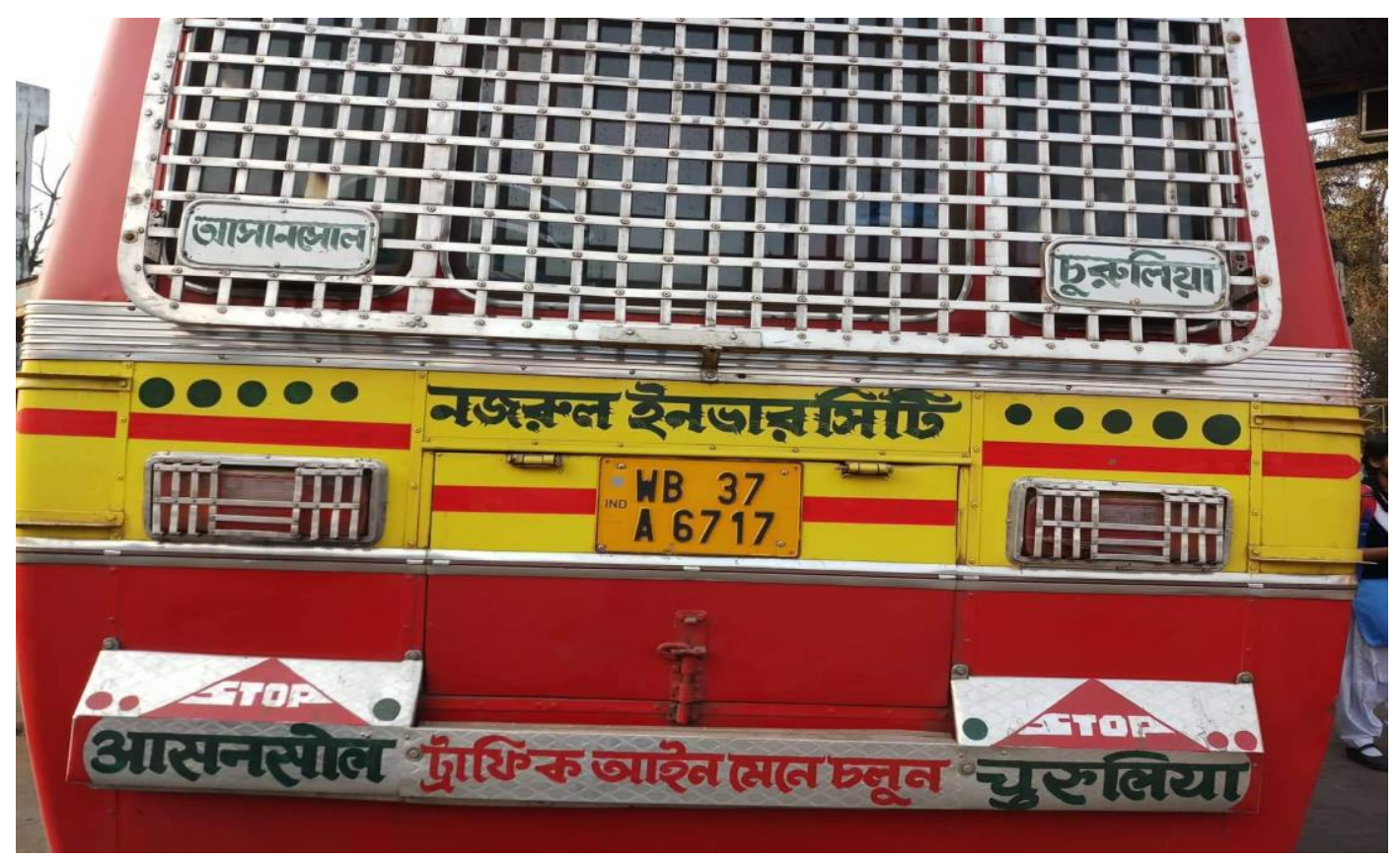

Figure 3: 'NAZRUL INVERSITY', ASANSOL BUS STAND, A BUS RUNNING FROM ASANSOL TO CHURULIA VIA KAZI NAZRUL UNIVERSITY, LENS: CANON 18-55 MM, DATE: 18/09/2019, SELF CLICKED.

So, to end my discussion I would like to refer to Derrida's neologistic term 'hauntology' that he used in his famous book Spectres of Marx. Derrida used this term in the context of Marx's proclamation in the very first line of The Communist Manifesto, "a spectre is haunting Europe- the spectre of Communism". (Marx \& Engels, 2002, p.27) However, in general terms 'hauntology' means the presence of the past that asserts itself as an absence in order to refer to a non-origin rather than an ontological presence. Here these native quirkish names haunt the present world-view of colonial and cultural violence in order to assert themselves into the public domain. Here the humanist hegemonic discourses of otherization and cultural-lingual violence work as the ontology that tries to subjugate the 'other' or in Derridean terms, "Of every concept, beginning with the concepts of being and time. That is what we would be calling here hauntology. Ontology opposes it only in a movement of exorcism. Ontology is a conjuration." (Derrida, 2006, p. 202) Manifestly then, I would like to conclude by saying that despite all the exorcism and suppression exercised by Eurocentric world-view, these names assert a sense of posthumanism and postcolonialism there by making these two major theoretical schools cut across each other.

\section{References}

Braidotti, R (2013). The Posthuman. Polity Press. 
Cudworth, E \& Hobden, S (2018). The Emancipatory Project of Posthumanism. Routledge. Davies, T (1997). Humanism. Routledge.

Derrida, J (2006). Spectres of Marx. Routledge Classics.

Dey, G. K (2010). BahonLipi. Ananda Publishers.

Foucault, M (1984). "Des EspaceAutres". Architecture/Movement/Continuete. (Trans.). Jay Miskowiec, "Of Other Spaces". https://web.mit.edu/allanmc/www/foucault1.pdf

- - -. (2002). The Order of Things: An Archaeology of Human Science. Routledge Classics. Ferrando, F (2019). Philosophical Posthumanism. Bloomsburry Academic.

Ghosh, A (2019). Gun Island. Penguin Random House.

Gordon,C (Ed.). (1980). Power/Knowledge: Selected Interviews and Other Writings 19721977 by Michel Foucault. Pantheon Books.

Harari, Y. N (2011). Sapiens: A Brief History of Humankind. Penguin Random House.

Marx, K. \&Engels, F (2002). The Communist Manifesto. Penguin Classics.

Said, E. W (2004). Humanism and Democratic Criticism. Columbia University Press.

Thiongo, N. W (2007). Decolonising the Mind: The Politics of Language in African

Literature, Worldview Publications.

\section{Bio-note}

Saikat Chakraborty is an integrated Mphil-Phd scholar in the Department of English, Kazi Nazrul University. He stood First Class First in his M.A exam in the year 2018. He qualified NET (LS) June, 2019. His areas of interest are Post humanities, Medical Humanities, Culture Studies, Absurd Literature and Literary Theory.

Email id: saikatchakraborty1995@gmail.com 